\title{
Neurocardiogenic Syncope: Frequency and Consequences of its Misdiagnosis as Epilepsy
}

\author{
Colin B. Josephson, Susan Rahey, R. Mark Sadler
}

\begin{abstract}
Background: Neurocardiogenic syncope (NCS) can be mistaken as a seizure. We reviewed the frequency and diagnostic consequences of this misdiagnosis. Methods: A retrospective review of outpatient adult epilepsy clinic charts (QEII Health Sciences Centre, Halifax, NS) was conducted to identify NCS patients referred with a provisional diagnosis of seizures. Charts were reviewed in detail with an emphasis on the consequences of misdiagnosis. Results: Of 1506 consecutive referrals to the epilepsy clinic, 194 (12.9\%) ultimately had a clinical diagnosis of NCS. Mean age was $38+/-16$ years (mean age of syncopal onset was $28+/-16$ years). Two-thirds of referrals were from primary care physicians (including emergency departments) and 18\% from neurologists. Thirty-five percent were prescribed antiepileptic drugs (AEDs) prior to referral with eight patients (4.1\%) experiencing hypersensitivity reactions. Three of five women had adverse pregnancy outcomes while taking AEDs. One-third of patients had restrictions placed on their driving privileges while 11 patients $(5.7 \%)$ had their employment interrupted. Diagnostic modalities used in the work-up included EEG (90\%), CT head (51\%), and MRI head (15\%). Conclusions: NCS is commonly misdiagnosed as epilepsy. Some patients had an incorrect diagnosis for $>10$ years. Patients with this misdiagnosis are often excessively investigated, inappropriately treated, and have unnecessary restrictions placed on driving and employment.
\end{abstract}

RÉSUMÉ: Syncope neurocardiogénique : fréquence et conséquences d'un diagnostic erroné d'épilepsie. Contexte : Une syncope neurocardiogénique (SNC) peut être prise à tort pour une crise convulsive. Nous revoyons la fréquence et les conséquences d'un tel diagnostic erroné. Méthodes : Nous avons effectué une révision rétrospective des dossiers de patients de la clinique externe d'épilepsie (QEII Health Sciences Centre, Halifax, NS) afin d'identifier les patients ayant présenté une SNC qui y ont été référés avec un diagnostic provisoire de crise convulsive. Les dossiers ont été révisés en détail, particulièrement en ce qui concerne les conséquences d'un diagnostic erroné. Résultats : On a posé ultérieurement un diagnostic de SNC chez 194 (12,9\%) de 1506 patients consécutifs référés à la clinique d'épilepsie. L'âge moyen des patients était de $38 \pm 16$ ans et l'âge moyen au moment du début des syncopes était de $28 \pm 16$ ans. Les deux tiers des patients avaient été référés par le médecin de première ligne (salle d'urgence inclusivement) et $18 \%$ par un neurologue. Des antiépileptiques avaient été prescrits à $35 \%$ des patients avant qu'ils ne soient référés à la clinique et 8 de ces patients $(4,1 \%)$ ont eu une réaction d'hypersensibilité. Trois femmes sur cinq ont eu des conséquences défavorables sur leur grossesse alors qu'elles prenaient des médicaments antiépileptiques. Un tiers des patients ont vu leurs privilèges de conduite automobile restreints et 11 patients (5,7\%) ont subi une interruption d'emploi. Les modalités diagnostiques suivantes ont été utilisées dans l'évaluation des patients : ÉEG (90\%), tomodensitométrie de la tête (51\%) et IRM de la tête (15\%). Conclusions : La SNC est souvent diagnostiquée à tort comme étant de l'épilepsie. Chez certains patients, le diagnostic erroné avait été posé plus de 10 ans auparavant. Les patients qui ont reçu un tel diagnostic subissent souvent une évaluation excessive, sont traités de façon inappropriée et se voient imposer des restrictions inutiles quant à leur privilèges de conduite automobile et d'emploi.

Can. J. Neurol. Sci. 2007; 34: 221-224

Neurocardiogenic (vasovagal/vasodepressor) syncope (NCS) is a reflex mediated loss of consciousness resulting from the failure of the autonomic nervous system to maintain adequate cerebral perfusion pressure. ${ }^{1,2}$ Excessive peripheral venous pooling of blood in combination with aberrant responses of mechanoreceptors to compensatory cardiac hypercontractility results in a paradoxical reflex bradycardia and drop in peripheral vascular resistance. ${ }^{3,4}$ The consequent cerebral hypoperfusion induces a transient loss of consciousness that is associated with abnormal movements (e.g. myoclonic jerks) in $12-90 \%$ of patients. ${ }^{2,5-10}$ Despite clinical guidelines that distinguish NCS from epileptic seizures (94\% sensitivity and specificity), misdiagnoses continue to occur with consequent overinvestigation and unwarranted treatment. ${ }^{11,12}$

From the Neuroelectrodiagnostic Unit (CBJ, SR), Capital Health Authority; Division of Neurology (RMS), Department of Medicine, Dalhousie University, Halifax, NS, Canada.

Received July 26, 2006. AcCePted in FinAl FORM February 24, 2007. Reprint requests to: $\mathrm{R}$. Mark Sadler, Division of Neurology, Dalhousie University, Room 3829 Halifax Infirmary, Queen Elizabeth II Health Sciences Centre, 1796 Summer Street, Halifax, Nova Scotia, B3H 3A7, Canada. 
Data from a United Kingdom tertiary care adult epilepsy clinic revealed that almost one-third of referrals for epilepsy management were incorrectly diagnosed. NCS constituted $28 \%$ (13/46) of misdiagnosed cases. ${ }^{7}$ Many of these patients were exposed to inappropriate anti-epileptic drug (AED) use and to physical, social, and economic adverse effects. Lack of similar North American data prompted an investigation into the rate and frequency of adverse effects that are associated with patients diagnosed with NCS after referral to a Canadian adult tertiary care epilepsy clinic.

\section{SubJects AND Methods}

This study consists of a retrospective review of all patients ( $\geq 18$ years of age) referred to an adult neurologist (RMS) whose predominant outpatient practice is epilepsy. All consecutive clinic charts (from 1988-2004) were reviewed; only those patients referred for epilepsy were included in this study. Patients were only categorized in the NCS group if their history was consistent with features generally accepted as characteristic for neurocardiogenic syncope ${ }^{13}$ (Table 1). Patients were excluded from analysis if an unequivocal diagnosis could not be made.

Data collection included demographic information, referral source, duration of diagnosis, and investigations. The impact of AED use, including adverse effects and use during pregnancy, was assessed through the history obtained at the clinic visit. Socio-economic impact was inferred by evaluating any suspension of driving privileges or employment.

Table 1: Clinical features commonly associated with neurocardiogenic syncope $\mathrm{s}^{13}$

Patient History

-History of lightheaded (presyncopal) spells while standing

-History of syncope or presyncope with definitive provocation (pain, prolonged standing or sitting, heat, exercise, medical procedures etc.)

Prodrome

-Subjective sense of an impending loss of consciousness

-Dimming or concentric loss of vision from periphery ("tunnel vision")

Onset

-Tinnitus or sensations that sounds appear "far away"

-Gradual progression towards loss of consciousness (30 sec minutes)

Loss of Consciousness

-Flaccid loss of tone resulting in slumping to the ground

-Brief tonic phase and/or associated myoclonic jerks

-May be incontinent

-Brief duration (average $\sim 12$ seconds)

Recovery

-Rapid recovery of consciousness

-Repeated loss of consciousness if sit or stand immediately after 1st event

-Absent or mild post-event disorientation or confusion

-Pallor, headache, weakness, or fatigue

-Can progress to anoxic seizures if held upright

\section{RESULTS}

A total of 1506 consecutive adult epilepsy patient charts were reviewed. Neurocardiogenic syncope was diagnosed in 194 $(12.9 \%)$ patients. Confirmed epilepsy $(\sim 80 \%)$ and psychogenic pseudoseizures $(\sim 7 \%)$ comprised the vast majority of additional cases. There were no known cases of cardiac arrhythmias causing transient loss of consciousness in our NCS referral population.

Demographic information is displayed in Table 2. The average age of the NCS population was $38+/-16$ years of age at clinic visit with a mean age of syncope onset of $28+/-16$ years. Over $30 \%$ (31.4\%) had repeated episodes of syncope prior to referral. The most common source of referral was from family practitioners $(\mathrm{n}=114)$. General neurologists $(\mathrm{n}=35)$ and emergency room physicians $(n=17)$ were other common sources of referral (Figure 1).

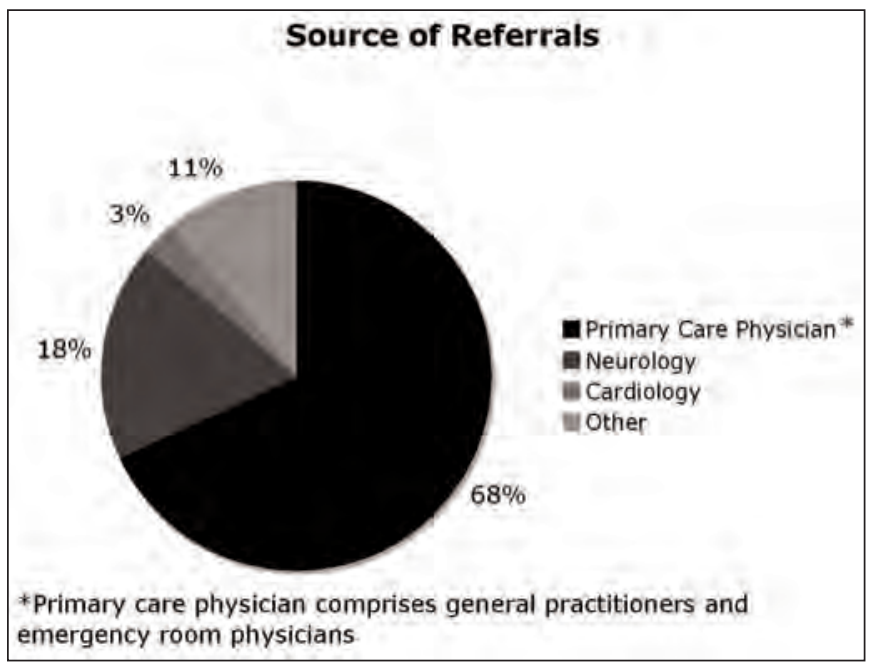

Figure: Breakdown of referral sources for patients $(n=194)$ initially diagnosed with epilepsy by the referring physician. All patients were determined to have neurocardiogenic syncope following assessment in an adult tertiary care epilepsy clinic.

Diagnostic modalities arranged prior to referral included EEG in 175 patients (90\%), CT of the head in 99 patients (51\%) and MRI of the head in 30 patients $(15 \%)$. Incidental findings were found on EEG, CT, and MRI in $14(8 \%), 7$ (7\%), and $4(13 \%)$ patients respectively (Table 2).

Sixty-seven (35\%) of patients were treated with AEDs prior to referral to the epilepsy clinic (Table 3). One-fifth of patients had been treated despite only one episode of NCS. Phenytoin (n $=45)$ and carbamazepine $(n=36)$ were the most frequently used medications. Adverse effects were reported in 35 of the 67 treated patients $(52 \%)$. Idiosyncratic reactions (unusual nondose-related individual reactions to the medication) and hypersensitivity rashes were the most commonly reported $(\mathrm{n}=$ $38)$, while dose-related reactions $(n=3)$ were less common 
Table 2: Demographics of patients referred to a tertiary care Canadian adult epilepsy clinic who were determined to have neurocardiogenic syncope $(n=194)$. Included are diagnostic tests requested by the referring physician

\begin{tabular}{lr}
\hline Gender & $48 \%: 52 \%$ (Male : Female) \\
Mean Age at Patient Evaluation (years) & $38+/-16$ \\
Mean Age at Syncope Onset (years) & $28+/-16$ \\
& \\
Proportion of Epilepsy Referrals & \\
& \\
Diagnostic Modalities Arranged & $194 / 1506(12.9 \%)$ \\
Prior to Referral (\% of Total) & $14(9 \%) *$ \\
EEG & $99(51 \%)$ \\
Incidental Findings & $7(7 \%)^{* *}$ \\
CT Head & $30(15 \%)$ \\
Incidental Findings & $4(13 \%)^{* * *}$ \\
MRI Head & \\
Incidental Findings &
\end{tabular}

*Incidental findings on EEG included non-specific temporal dysrhythmias and wicket spikes; **Incidental findings on CT included one case of a suspected mass at the cerebello-pontine angle, hydrocephalus, and patchy leukoencephalopathy; ***Incidental findings on MRI included enlarged Virchow-Robin spaces, an area of temporal cortical dysplasia, and ventricular dilation.

(Table 3). Five women became pregnant while taking AEDs. None of these patients reported pregnancy as a result of oralcontraceptive pill failure. Three pregnancies had adverse outcomes (two cases of spontaneous abortion and one case of congenital left-sided hemiplegia; Table 3).

Socioeconomic consequences of the misdiagnosis included restrictions placed on employment and driving. Twenty-seven patients had their license formally revoked (through a letter written to the provincial Department of Motor Vehicles) while 38 patients had their license informally restricted on the advice of the referring physician. Job restrictions were placed on 11 $(5.7 \%)$ patients as a result of transportation $(n=8)$ or health concerns $(n=3)$.

\section{Discussion}

A thorough history and physical examination is usually sufficient to distinguish NCS from epileptic seizures ${ }^{13}$ (Table 1). A diagnosis of NCS was easily obtained within one clinic visit in over $90 \%$ of cases using a focused and directed history. Adjunct investigations such as tilt table testing, EEG, CT, and MRI are rarely necessary, especially if published clinical guidelines are
Table 3: A summary of anti-epileptic medication treatment used prior to first outpatient assessment $(n=194)$

\begin{tabular}{lr}
$\begin{array}{l}\text { Number treated } \\
\text { (\% of total) }\end{array}$ & $67(35 \%)$ \\
$\begin{array}{l}\text { Number exposed to Polytherapy } \\
\text { (\% of treated) }\end{array}$ & $27(40 \%)$ \\
Agents used for monotherapy and/or polytherapy (n) & \\
$\quad$ Phenytoin & $45(42 \%)$ \\
$\quad$ Carbamazepine & $36(33 \%)$ \\
$\quad$ Phenobarbital & $11(10 \%)$ \\
$\quad$ Valproic Acid & $8(7 \%)$ \\
$\quad$ Clobazam & $3(3 \%)$ \\
$\quad$ Clonazepam & $2(2 \%)$ \\
$\quad$ Gabapentin & $1(1 \%)$ \\
$\quad$ Lamotrigine & $1(1 \%)$ \\
$\quad$ Nitrazepam & $1(1 \%)$ \\
Number reporting side-effects & $35(52 \%)$ \\
(\% of treated) & \\
Reported side-effects (n) & \\
$\quad$ Dose-related and Idiosyncratic & $27(77 \%)$ \\
Hypersensitivity & $3(9 \%)$ \\
Multiple side-effects & $5(14 \%)$ \\
Number exposed to AEDs during pregnancy & $5(5 \%)$ \\
(\% of all females) & \\
Pregnancy outcomes in patients exposed to AEDs (n = 5) & \\
Spontaneous abortion & \\
Congenital Hemiplegia & $(40 \%)$ \\
\hline
\end{tabular}

applied. ${ }^{5,7}$ While requisition of adjunct testing prior to referral need not be discouraged, it should only be ordered in those circumstances dictated by the clinical history. These investigations are redundant and economically inefficient if the case can be resolved by history alone. Physicians not familiar with the diagnostic limitations of the EEG may be more likely to inappropriately diagnose epilepsy and prescribe AEDs based on normal variant phenomena or non-specific abnormalities.

This phenomenon of inappropriate diagnosis and treatment has been demonstrated in previous publications from the United Kingdom. A population-based study in Cheshire, England, demonstrated that, after specialist review, $23 \%$ of the total population diagnosed with epilepsy were misdiagnosed. The diagnosis was questionable in an additional $12 \% .{ }^{14}$ A study conducted in Manchester, England, demonstrated that $36.1 \%$ of patients taking AEDs for presumed epilepsy were experiencing "blackouts" secondary to NCS. $^{6}$ An overall epilepsy misdiagnosis rate in Liverpool, England, was $26.1 \%$. Neurocardiogenic syncope constituted $28.2 \%$ of the total 
misdiagnosed cases. ${ }^{7}$ Exposure to AED and lifestyle restrictions was common in this population.

Our study suggests that paroxysmal attacks of syncope continue to be mistaken as epilepsy. In total, $13 \%$ of all referrals to a Canadian tertiary adult epilepsy clinic were diagnosed with NCS. This number is consistent with those reported in population studies ${ }^{14,15}$ or specialist clinics. ${ }^{7}$ Some of our patients carried a diagnosis of epilepsy for over ten years. While primary care physicians constituted the largest referral source, general neurologists and neurosurgeons represented the second highest source of referral (42/194 referrals) for management of epileptic seizures.

One-third of patients with NCS at our clinic were treated with AEDs prior to referral. Over one-half $(52 \%)$ of treated patients reported adverse reactions that resolved with cessation of the AED. The potential teratogenic effects of AEDs are well known. ${ }^{16}$ Five women in the present study either became pregnant while on an AED or had been prescribed an AED while pregnant. Although a cause and effect relationship cannot be established in a retrospective analysis, two of the pregnancies resulted in spontaneous abortions and one child was born with left-sided hemiplegia. Caution must be emphasized in prescribing AEDs to women of child-bearing age.

Nova Scotian provincial law does not mandate that patients with epilepsy be reported to the Department of Motor Vehicles. Most referring physicians invoked informal arrangements for license restriction (37/64 patients) rather than official letters to the Department of Motor Vehicles. Provincial law does stipulate that that those patients with a single episode of loss of consciousness may be allowed to operate motor vehicles providing the condition is felt to be benign. Those with more than one syncopal episode should avoid driving until the cause has been investigated and corrective measures taken.

Many employers still consider epilepsy to be an occupational liability and believe it should be reportable to management irrespective of whether it is in remission. ${ }^{17}$ Forced leave of absence was relatively common in our patient population $(6 \%)$, a situation complicated by the fact that individuals given an erroneous diagnosis of epilepsy may not be able to regain their previous source of employment and may have difficulties finding a new vocation.

By design, this retrospective study was not intended to determine the prevalence of NCS in the general population nor the percentage of these cases that are misdiagnosed as epilepsy. Rather, it was meant to illustrate that many cases of presumed epilepsy actually represent simple NCS. Our impression is that the diagnostic failures in this case series resulted from incomplete history taking (from the patient and/or a witness) or a lack of familiarity with the characteristics of syncope ${ }^{13}$ (Table 1).

In many cases there appeared to be an overemphasis on the loss of consciousness and resolution of the event with little attention paid to prodromal features, precipitating events and associated medical history. Guidelines now exist that use clinical history alone to distinguish NCS from seizures (94\% sensitivity and specificity; Figure 3) or other forms of syncope $(89 \%$ sensitivity and $91 \%$ specificity). ${ }^{11,12}$ Despite this, NCS is still commonly mistaken for epileptic seizures even though the conditions rarely coexist in the same patient. ${ }^{18}$ Neurocardiogenic syncope is estimated to constitute $6 \%$ to $39 \%$ of cases of presumed epilepsy depending on the population studied ${ }^{19}$ and therefore erroneous diagnosis may lead to inappropriate treatment with social and economic stigmatization. Continued medical education courses and publications should be designed to correct these knowledge deficiencies.

\section{REFERENCES}

1. Grubb BP, Karas B. Clinical disorders of the autonomic nervous system associated with orthostatic intolerance: an overview of classification, clinical evaluation, and management. Pacing Clin Electrophysiol. 1999; 22: 798-810.

2. Lempert T, Bauer M, Schmidt D. Syncope: a videometric analysis of 56 episodes of transient cerebral hypoxia. Ann Neurol. 1994; 36: $233-7$.

3. Lurie KG, Benditt D. Syncope and the autonomic nervous system. J Cardiovasc Electrophysiol. 1996; 7: 760-76.

4. Kosinski D, Grubb BP, Temesy-Armos P. Pathophysiological aspects of neurocardiogenic syncope: current concepts and new perspectives. Pacing Clin Electrophysiol. 1995; 18: 716-24.

5. Krahn AD, Klein GJ, Yee R, Skanes AC. Randomized assessment of syncope trial: conventional diagnostic testing versus a prolonged monitoring strategy. Circulation. 2001; 104: 46-51.

6. Zaidi A, Clough P, Cooper P, Scheepers B, Fitzpatrick AP. Misdiagnosis of epilepsy: many seizure-like attacks have a cardiovascular cause. JACC. 2000; 36: 181-4.

7. Smith D, Defalla BA, Chadwick DW. The misdiagnosis of epilepsy and the management of refractory epilepsy in a specialist clinic. Q J Med. 1999; 92: 15-23.

8. Chadwick D, Smith D. The misdiagnosis of epilepsy - the rate of misdiagnosis and wide treatment choices are arguments for specialist care of epilepsy. BMJ. 2002; 324: 495-6.

9. Grubb BP. Neurocardiogenic syncope. NEJM. 2005; 352: 1004-10.

10. Bergfeldt L. Differential diagnosis of cardiogenic syncope and seizure disorders. Heart. 2003; 89: 353-8.

11. Sheldon R, Rose S, Ritchie D, Connolly SJ, Koshman M-L, Lee $\mathrm{MA}$, et al. Historical criteria that distinguish syncope from seizures. J Am Coll Cardiol. 2002; 40: 142-8.

12. Sheldon R, Rose S, Connolly S, Ritchie D, Koshman M-L, Frenneaux M, for the Syncope Symptom Study Investigators. Diagnostic criteria for vasovagal syncope based on a quantitative history. Eur Heart J. 2006; 27: 344-50.

13. Bleck TP. Syncope. In: Epilepsy: a comprehensive textbook. Engel J Jr., Pedley TA, editors. Lippincott Raven-Publishers. 1997, Philadelphia, PA.

14. Scheepers B, Clough P, Pickles C. The misdiagnosis of epilepsy: findings of a population study. Seizure. 1998; 7: 403-6.

15. King MA, Newton MR, Jackson GD, Fitt GJ, Mitchell LA, Silvapulle MJ, et al. Epileptology of the first-seizure presentation: a clinical electroencephalographic and magnetic resonance imaging study of 300 consecutive patients. Lancet. 1998; 352: 1007-11.

16. Perucca E. Birth defects after prenatal exposure to antiepileptic drugs. Lancet Neurol. 2005; 4: 781-6.

17. Jacoby A, Gorry J, Baker GA. Employers' attitudes to employment of people with epilepsy: still the same old story? Epilepsia. 2005; 46: 1978-87.

18. Gestaut H, Fischer-William M. Electro-encephalographic study of syncope. Its differentiation from epilepsy. Lancet. 1957; ii: 1018-25.

19. Guberman A, Starreveld E. Differential diagnostic considerations in patients with intractable epilepsy. In: Intractable Epilepsies, Warren T. Blume, editor. Advances in Neurology vol 97; Lippincott Williams, and Wilkins. 2006, Philadelphia, PA. 